\title{
LANGUAGE AND SCIENTIFIC COMMUNICATION: THE CASE OF THE REPRINT REQUEST
}

\author{
J. SWALES \\ The English Language Institute, \\ The University of Michizan, Ann Arbor, MI 48109 (USA)
}

(Received June 10, 1987)

\begin{abstract}
This paper reports on a study of Reprint Requests (RRs). It is estimated that tens of millions of RRs are mailed each year, most being triggered by Current Contents. A sample of RRs generated by three papers, plus a questionnaire-survey of the requesters for one paper, form the basis of this study into language use patterns in the RR genre. English is ubiquitous, German and French infrequent, Russian and Spanish rare. This language data is significant because it provides unit-level language decision making (as opposed to that at other levels). Various applications of RR research are discussed, including its relevance to the issue of "Third World Science".
\end{abstract}

\section{Introduction}

A Reprint Request (RR) is a request for a copy or reprint of a publication mailed by a scholar or researcher to the author (or authors) of that publication. Typically, the request is carried by a printed or duplicated card with spaces provided for inserting the name of the author, the details of the publication and the name of the requester. As Onuigbo ${ }^{1}$ observes:

There is no doubt that preprinted request cards are part and parcel of the information traffic occurring in science today. Indeed they dominate the scene. For instance, so great is their predominance that I received only nine letters, in contrast to 1,014 cards from the United States.

(Onuigbo, Ref. ${ }^{2}$ p. 95)

In the case of the present sample, the proportion of nonprinted cards (either letters or handwritten or typed postcards) is a little larger, but still small: eight such requests out of a total of 139 .

It would be helpful at the outset to have a sense of the annual size of this Reprint Request traffic among the world's research community. One way of obtaining a rough estimate is to utilize data available from the Institute for Scientific Informa- 


\section{J. SWALES: LANGUAGE AND COMMUNICATION}

tion. Among the ISI's products is a peelable Request-A-Print card which it offers for sale. According to the Director, 1340000 such cards were sold in 1985 (Garfield, personal communication). As these peelable self-adhesive cards have been available for a number of years, it can be cautiously assumed that sales of 1.34 million represent replenishment of stock and so indicate an approximate level of use. If we can now ascertain the percentage of Request-A-Prints among the total of RRs we can produce some sort of estimate of the annual traffic. Onuigbo ${ }^{2}$ found 62 ISI cards in a collection of 2049 RRs; in the present smaller sample there were four out of 139 . Interestingly, in both cases the percentage of Request-A-Prints was about 3\%. If we assume that ISI cards constitute as much as $5 \%$ of the total traffic, then the world total might be in the range of 25 to 30 million cards sent a year; if we assume that ISI cards only constitute $2 \%$ of the total traffic, the world annual total would rise to $60-70$ million RRs. Either way, it seems reasonable to conclude that tens of millions of RRs are dispatched each year. Thus, the genre may be relatively simple in format, but it is certainly not small.

Nor is the genre without its consequences. Whilst some authors may throw away many or most of the RRs they receive, other authors are extremely responsive. The main informant in this study, Dr. Robert Fogel (an American biologist) is happy to respond to RRs, although he is somewhat leery of requests from individuals he believes to be graduate students and is disinclined to respond fully to requests for multiple copies. On the other hand, he is not too adverse to including in his return package 'papers on related topics' if asked to do so and when supplies are available. Additionally, in his two main areas, Fungal Ecology and Systematics, Dr. Fogel maintains mailing lists; by early 1987, the mailing list for the former consisted of 113 names and addresses. It is not surprising, therefore, that Dr. Fogel may order up to 300 reprints for his ecology papers. Dr. Fogel believes that responding to RRs is "good advertising" and is therefore worth the time, trouble and cost that is incurred. More specifically, he believes that if fellow researchers have reprints of his papers to hand, they are more likely to cite them than would be the case if they had to look up his publications in a library.

Swales $^{3}$ describes the results of a questionnaire sent to people who asked for a reprint of a paper published in Scientometrics in 1985. Although only 12 of the 35 questionnaires were returned, (a response rate of 34\%), eleven of the 12 said that they received at least $50 \%$ of the papers they had requested. Even if the actual response rate found in a more representative sample is only $25 \%$, this percentage would nevertheless indicate that several million reprints are mailed out each year as a result of reprint requests. And of course this estimate excludes those mailings instigated by authors themselves. 
Given the orders of magnitude apparently involved, the economic effects of the RR system are various and considerable. The system will have an impact on mail services designed to service research centers and on the administrative expenses of those centers. The system can lead to the creation of large and bulky personal libraries - a Swiss medical professor responding to the questionnaire claimed to send out $10000 \mathrm{RRs}$ a year and to have been using the system for 15 years. The intellectual effects are not so tangible but may occasionally be significant, even if there is clearly a great deal of wastage in the system. Many (perhaps even a majority) of the RRs may finish up virtually unread or cursorily dismissed. This is because the available evidence seems to suggest the development of a RR System can be linked with the expansion of increasingly computerized bibliographic and abstracting tools, and may also be connected with "meta-monitoring of scientific communication processes by research units" (Charles Bazerman, personal communication). It was presumably some such scanning of titles and key-words that lead to an Institute concerned with rubber research to request a reprint of a paper written by a discourse analyst colleague on cohesion.

In this triggering process the role of Current Contents seems crucial. A neat illustration of its importance as a source of RRs is provided by Onuigbo. ${ }^{4}$ In two of Onuigbo's articles indexed in Current Contents there occurred a printing error; in one instance a proper name was mis-spelled and in the other a preposition was deleted. Onuigbo found that in 26 cases there was insufficient title to indicate the source for the RR, in 52 cases the printing error was repeated (thus indicating a Current Contents source) and in only 9 cases was the correct original title preserved (thus indicating a primary rather than secondary source). It is not surprising that reliance on minimal information in secondary sources can lead to many disappointments. On the other hand, an initial and impersonal RR may have repercussive effects; it may lead to the reciprocal return of papers, a growth of correspondence, arrangements to meet at conferences and, in a few instances, to that most satisfactory outcome - collaborative research. On occasion, "Tall oaks from little acorns grow".

The Reprint Request is at the same time both institutionalized and yet restricted to certain sectors of the academic world. Convincing evidence for the former claim lies in the fact that the great majority of RRs are printed by departments (and other types of research units) for the use of their members. For instance, in only six of the 127 printed RRs in the current sample was the name of the researcher also printed at the top of the return address; much more typically the name of the requester is hand-written, typed or rubber-stamped. With few exceptions, therefore, RRs are produced by institutional organizations and not by individuals. On the other hand, RRs are restricted to certain fields, typically Medicine, the Life and Physical Sciences and Engineering, with perhaps growing use in the "harder" social sciences 


\section{J. SWALES: LANGUAGE AND COMMUNICATION}

such as psychology. In the humanities, methods of contact and exchange tend to be much more individual and personal; in my own area, Applied Linguistics, I know of only one colleague who uses RRs - and inevitably enough his anomalous position has required him to print his own cards. In Applied Linguistics, it is customary to receive 20-30 free reprints of papers and not to order additional copies. We may give some of these to colleagues whom we work with, keep a few, and mail the rest to a relatively small number of others whom we believe to have'a particular interest in the research topic. Concomitantly, we do not expect to receive very many reprint requests; in my own case, I have never received more than six RRs for any paper I have published except in one case. That exception sparked by interest in the genre of reprint requests and forms part of the corpus that I have analyzed.

\section{The corpus}

The main corpus consists of 127 printed RRs generated as a result of the publication of three papers, whilst the subsidiary corpus consists of 12 further requests of a different form (4 ISI Request-A-Prints and 8 more personal requests). The three papers are:

1. J. M. SWALES, English language papers and author's first language: Preliminary explorations, Scientometrics, 8 (1985) 91.

2. R. FOGEL, J. M. TRAPPE, Fungus consumption (mycrography) by small animals, Northwest Science, 52 (1978) 31.

3. R. FOGEL, Root turnover and productivity of coniferous forests, Plant and Soil, 71 (1983) 75 .

The fact that $I$ had received several times more RRs from readers of this Journal than from any other suggests that by publishing in Scientometrics I had entered another discourse community. Of the 33 printed RRs received as a result of the Scientometrics paper, 25 apparently emanated from those working in institutes or departments that were concerned with the medical or biological sciences, six from those in other sciences or branches of engineering, one from agriculture and one from psychology. Only the last could be considered as a person with a direct scholarly interest in the topic of the papers. This was Dr. Joachim Becker of Trier University, West Germany, who had already published several articles on the role of German and English in disseminating Western German psychological research. There were no linguists or sociolinguists; nobody working in information or library science; and nobody directly concerned with the teaching of either English or academic writing. Apparently then the requesters were likely to have only a potential, minor or marginal interest in the topic. 
As already mentioned, the unexpectedness of this response led me to poll the requesters about their $R R$ habits and motivations. Indeed, a further reason for distributing a questionnaire was my guess that only 3 of the 33 were native speakers of English. Nine of the 12 respondents mentioned that they selectively sent RRs for Scientometrics articles, thus corroborating the impression given by their place of work that they have a minor interest in scientometric matters. Eight checked an interst in international scientific communication and a somewhat different eight checked an interest in the communication problems of non-native speakers of English. Indeed, half referred to the "political" or "psychological" implications of being a NNS in the anglophone world of international research, one expressing his interest in reading the paper in the following gloomy terms: "to further define my handicaps"

The '78 Fogel paper was published in Northwest Science, which, as its name implies, is an interdisciplinary regional journal. The ' 83 paper was published in a specialized international journal produced in Britain.

The profile of requesters for the two Fogel papers was, as we might expect, more predictable. The majority worked in university departments concerned with pure or applied life sciences, whilst a minority were sent by national or regional research institutions outside the university network. The 1978 paper (Fungus consumption by small animals) drew in a number of requests from Health Institutes, and departments such as anthropology and psychology, and one from a Zoo. The 1983 paper (Root turnover and productivity of coniferous forests) naturally enough attracted many more requests from institutions concerned in some way with forestry, range science or agriculture.

The differences between the role and location of the three journals could be expected to have some effect on the provenance of the requests. Although this is undoubtedly the case with regard to Swales v. Fogel, it is much less obviously true with regard to Fogel '78 v. Fogel ' 83 . The figures for provenance (grouped into main areas of the world) are given in the following table.

Table 1

Provenance (main and supplementary corpus)

\begin{tabular}{lcccccccc}
\hline & USA & Canada & $\begin{array}{c}\text { N. \& W. } \\
\text { Europe }\end{array}$ & $\begin{array}{c}\text { E. Europe } \\
\text { \& Russia }\end{array}$ & $\begin{array}{c}\text { Latin } \\
\text { America }\end{array}$ & $\begin{array}{c}\text { Australia/ } \\
\text { Orient }\end{array}$ & Other & Total \\
\hline Swales '85 & 2 & 1 & 12 & 14 & 5 & 1 & Turkey & 36 \\
Fogel '78 & 34 & 4 & 4 & 0 & 2 & 2 & 0 & 46 \\
Fogel '83 & 31 & 6 & 9 & 4 & 1 & 5 & India & 57 \\
\hline Total & 67 & 11 & 25 & 18 & 8 & 8 & 2 & 139 \\
\hline
\end{tabular}




\section{J. SWALES: LANGUAGE AND COMMUNICATION}

The main origin of requests for the Scientometrics paper is clearly Europe, perhaps because the journal is edited in Eastern Europe and distributed from West Europe. However, the pattern of provenance for the two Fogel papers is perhaps less different than we might expect. U.S. provenance clearly predominates in both cases, while proportions for Canada and Latin America/the Pacific Rim are roughly equivalent. Although European requests do rise in the case of the Plant and Soil paper, they still only amount to 13 (in contrast to 37 from North America).

\section{Language choice in reprint requests}

For those with an interest in linguistic matters, an intriguing aspect of printed RRs is the language or languages chosen to express the request. If a multilingual format is chosen, the order of languages remains consistent in all RRs so far examined; in other words if German is the top language for the opening salutation, then it will remain the first language throughout. In the following table this order is represented by $1 \mathrm{~L}$ to $4 \mathrm{~L}$.

As can be seen, English was used on all the RRs, and was the only language found on monolingual cards. In fact, overall $80 \%$ of all the RRs were monolingual English,

Table 2

Language use patterns in the main corpus $(N=127)$

\begin{tabular}{lrrrrrrr} 
& & \multicolumn{5}{c}{ Multilingual } & Total \\
\cline { 3 - 6 } \cline { 4 - 6 } & & $1 \mathrm{~L}$ & $2 \mathrm{~L}$ & $3 \mathrm{~L}$ & $4 \mathrm{~L}$ & \\
\hline English & 102 & 4 & 18 & 3 & 0 & 127 \\
German & 0 & 10 & 3 & 6 & 0 & 19 \\
French & 0 & 8 & 1 & 5 & 3 & 17 \\
Russian & 0 & 2 & 3 & 0 & 1 & 6 \\
Spanish & 0 & 1 & 0 & 0 & 1 & 2 \\
\hline Total & 102 & 25 & 25 & 14 & 5 & \\
\hline
\end{tabular}

although there was some difference between the three subsamples (Swales 55\%, Fogel '78 90\%, and Fogel ' 83 85\%). On the basis of an earlier analysis of the Scientometric subsample ${ }^{3}$ it was hypothesized that if the card was multilingual, English. would not be the first language. However, as Table 2 shows, the larger corpus produced four counter-examples to this suggestion. Two might be explained away in 
terms of special circumstance. One is the single U.S. multilingual card in the corpus (English-German-French) and another is a card from British Columbia (English-French). The other Canadian cards from the central provinces are all monolingual English, while two of the three cards from Quebec are French-English. It would be natural for Anglophone Canadian locations to opt for an English-French order if they would wish to recognize the spirit of bilingualism. The two other cards that placed English first came from Czechoslovakia and Austria, were quadrilingual, and cannot be accounted for. (I have also seen - outside the corpus - a Dutch card that is ordered EnglishFrench-German). It therefore now seems that it would be unusual, but not impossible, to find a multilingual card which places English on the top line.

Table 2 shows that four other languages occurred in addition to the ubiquitous English. These multilingual cards originated principally in Westem and Eastern Europe; and, as might be expected, the francophones tended to place French first, while German speakers did the same for German. The Scandinavian cards were typically monolingual English. The six cards that carried a Russian-language request all came from the Eastern block. Only one of the 10 cards emanating from Hispano-portuguase speaking areas employed Spanish, suggesting that Spanish has very marginal status as a Reprint Request language (the other Spanish card came from a French university). Obviously enough, other potential RR languages, such as Japanese, Italian or Chinese, did not occur.

\section{Discussion}

The Reprint Request has all the characteristics of a wellestablished genre. It has size and stability, and has, within the discourse communities in which it oocurs, a narrowly-defined and mutually understood role as being a 'one-shot' request for a simple mailing response. RRs are always expressed in English, but in a minority of cases other languages maỹ be used as well. The maximum number of languages used in this corpus was four (5 instances). German and French are relatively common, Russian and Spanish rare. If a card is multilingual, English is likely to be the second and not the first language listed. Language choice can be related to the location of the institution that generates the RR and to the linguistic and geopolitical circumstances that affect that location.

The reasons for the massive quantity of RR traffic in the world today - much of it international - remain somewhat obscure. My informant Dr. Fogel has explained why he responds positively to RRs, but he also knows of colleagues who are considerably less accommodating. Certainly, the system has its critics: 'I am not alone in not sending reprints to North America'.5 The final question in my questionnaire asked those who sent RRs to comment on the advantages of the RR system to them. 


\section{J. SWALES: LANGUAGE AND COMMUNICATION}

The most common types of stated advantage were access to papers that would otherwise be difficult to get hold of (i.e. journals not carried by the institutional library etc) and the fact that the reprints were immediately available and to hand. The latter observation, of course, gives substance to Dr. Fogel's premise that if papers are to hand, they are more likely to be cited. A number of respondents also mentioned the time element (quick in contrast to inter-library loan; time needed to travel to the library; time lost by xeroxing). The Polish respondent referred to the scarcity of photocopiers. There were, in addition, a number of more individual advantages. One person emphasized the much better quality of photographs in reprints rather than photocopies, another the fact that he often lent the reprints to his students, and a third referred to "the personal contact with colleagues" that the RR system engendered - this last an indication of the system's disguised potentiality for networking.

Applications of Reprint Request analyses can take several directions: The RR phenomenon has a skewed distribution in the academic and research worlds; therefore, its variable occurrence and degree of institutionalization will provide additional evidence for those concerned with mapping disciplinary cultures and for those interested in the communicative practices of scholars and researchers in different fields. Second, the RR offers a useful research site for rhetoricians involved in establishing the effectiveness or otherwise of communications within institutionalized settings. For instance, Jablin and Krone ${ }^{6}$ have investigated relationships between rhetorical aspects of job rejection letters and the reactions of their recipients. A comparable study of rhetorical and other aspects of RRs and the reactions of their recipients would be equally valuable.

Third, the RR provides unusual information about sociolinguistic patterns of language use in international research. At present much of the available evidence derives from higher-order policies, in particular the language policies of editorial boards, Abstracting and Indexing services, and international scientific and scholarly associations ${ }^{7-10}$ or from individual coping strategies. ${ }^{11}$ As the Reprint Request is produced by a local unit or department we thus obtain a different perspective on language decisions and their possible motivations.

Finally, and perhaps most directly, the analysis of the RR has relevance for those concerned with both the connectivity and visibility of Third World Research. ${ }^{12-13}$ Evidence from both the Onuigbo corpus and present corpus suggests that the Third World produces few reprint requests. If we further recognize ${ }^{14}$ that many nonnative speakers with limited English writing abilities find it difficult - often for cultural reasons - to initiate academic correspondence with potential colleagues in other parts of the world, then we can see the reprint request as an inexpensive and undemanding mechanism for 'breaking the ice'. Thus, tall oaks from little acorns grow. 
I would like to thank Dr. Robert Fogel, Division of Biological Sciences, University of Michigan, for giving me access to his records and for many valuable observations.

\section{References}

1. W. I. B. ONUIGBO, The utilization of request-a-print, Social Studies of Science, 14 (1984) 94.

2. W. I. B. ONUIGBO, Reprint Requests - a tool for documentation. International Forum on Information and Documentation, (1985) 7.

3. J. SWALES, ESP in the Big World of Reprint Requests. English for Spectfic Purpowex, 5 (1986) 81.

4. W. I. B. ONUIGBO, Printer's devils and Reprint Requests, Joumal of the Americen Society for Information Science, 33 (1982) 58.

5. M. ESSEX-LOPRESTI, Why request reprints? British Medical Joumal, 283 (1981) 790.

6. F. M. JABLIN, K. KRONE, Characteristics of rejection letters and their effects on job applicants, Written Communication, 1 (1984) 387.

7. R. B. BALDAUF, Linguistic constraints on participation in Psychology, The American Psychologist, 41 (1986) 220.

8. R. B. BALDAUF, B. H. JERNUDD, Language use patterns in the fisheries periodical literature, Scientometrics, 5 (1983) 245.

9. J. SWALES, English as the international language of research, RELC Joumal, 16 (1985) 1.

10. J. MAHER, The development of English as an international language of Medicine, Applied Linguistics, 7 (1986) 206.

11. M-J. St. JOHN, Writing processes of Spanish scientists publishing in Enchish, English for Specific Purposes, (forthcoming).

12. M. MORAVCSIK. Strengthening the Coverage of Third World Science, The University of Oregon, Eugene, USA, 1986.

13. L. VELHO, The author and the beholder: How paradigm commitments can infuence the interpretation of research results, Scientometrics, 11 (1987) 39.

14. M. BLOOR, English Language needs in the University of Condoba: The Report of a Survey, The University of Aston, Birmingham, England, 1984. 